\title{
Fatores que afetam as decisões individuais de realizar viagens a pé: estudo qualitativo
}

\author{
Ana Margarita Larrañaga ${ }^{1}$; José Luis Duarte Ribeiro²; \\ Helena Beatriz Betella Cybis ${ }^{3}$
}

\begin{abstract}
Resumo: Este trabalho apresenta uma pesquisa qualitativa desenvolvida com o objetivo de identificar os fatores que influenciam a decisão de realizar viagens a pé. Para o desenvolvimento do trabalho foi utilizada a técnica de entrevistas individuais, que permitiu coletar as opiniões e percepções de diferentes grupos de usuários segmentados por idade e região de residência. Os fatores identificados foram classificados e hierarquizados de acordo com a intensidade e freqüência das manifestações dos entrevistados. A hierarquização permitiu identificar os fatores que exercem maior e menor influência na decisão de caminhar e aqueles que são essenciais ou inibidores da escolha deste modo. Os resultados da pesquisa permitem concluir que as características atitudinais ou de estilo de vida dos indivíduos influenciam fortemente o padrão de deslocamentos a pé. Os elementos que caracterizam a estrutura físico /urbana do bairro não são suficientes para explicar o padrão de deslocamentos em centros urbanos. É fundamental considerar as características sócioeconômicas e de estilo de vida dos usuários na elaboração de projetos urbanísticos e de transportes que visem preservar o ambiente de forma sustentável.
\end{abstract}

Abstract: This paper presents a qualitative research, developed to identify the factors that influence the decision of walking as a mode of travel. The data collection was based on individual interviews technique. This approach allowed to collect opinions and perceptions of different user groups, organized according age and area of residence. The identified factors were classified and ordered according to frequency and intensity. The ordering process enabled to identify the more influent factors on the decision of walking and the factors that inhibit the choice of walking as a travel mode. The results showed that attitudinal or lifestyle characteristics strongly influence walking behavior. The analysis of the physical/urban structure of the neighborhood is not sufficient for carry out an adequate planning in urban centers. It is fundamental to consider socio-economic and lifestyle characteristics of user to develop transport and urban projects that aim to preserve the environment in a sustainable form.

\section{INTRODUÇÃO}

A predominância do automóvel na circulação viária é um grave problema na maioria das cidades de médio e grande porte. O excesso de automóveis compromete o meio ambiente, a economia, a saúde e as condições de segurança da circulação. Para reduzir os volumes de tráfego e atenuar as externalidades produzidas pela operação do sistema de transporte, é necessário alterar os padrões de mobilidade atuais, que incentivam o uso do automóvel em detrimento de modos mais sustentáveis. Em contraponto ao uso excessivo do automóvel, as viagens a pé oferecem vários benefícios para o individuo e para a sociedade (Cao et al., 2006; Litman, 2003), melhoram a qualidade de vida, reduzem os custos de transporte, os impactos ambientais e oferecem

\footnotetext{
${ }^{1}$ Ana Margarita Larrañaga, Universidade Federal do Rio Grande do Sul, Programa de Pós-graduação em Engenharia de Produção, Laboratório de Sistemas de Transportes, Porto Alegre, RS, Brasil. (e-mail: analarrau@gmail.com).

2 José Luis Duarte Ribeiro, Universidade Federal do Rio Grande do Sul, Programa de Pós-graduação em Engenharia de Produção, Laboratório de Otimização de Produtos e Processos, Porto Alegre, RS, Brasil. (e-mail: ribeiro@producao.ufrgs.br).

${ }^{3}$ Helena Beatriz Betella Cybis, Universidade Federal do Rio Grande do Sul, Programa de Pós-graduação em Engenharia de Produção, Laboratório de Sistemas de Transportes, Porto Alegre, RS, Brasil. (e-mail: helenabc@producao.ufrgs.br).
}

Manuscrito recebido em 7/12/2008 e aprovado para publicação em $1 / 6 / 2009$. Este artigo é parte de TRANSPORTES, volume XVII, número 2, dezembro de 2009. ISSN: 1415-7713. maior eqüidade de acesso às atividades urbanas (Handy, 2002).

O surgimento e o intenso uso dos veículos automotores aumentaram a mobilidade da população urbana. Em nenhum momento, porém, a condição natural de andar a pé foi abandonada. Andar a pé constitui uma forma indispensável de transporte para a maioria da população, seja como modo principal do deslocamento, ou complementando viagens realizadas através de transporte público ou automóvel. Pesquisas de origem-destino realizadas em cidades brasileiras mostram que mais de $30 \%$ dos deslocamentos em áreas urbanas são feitos a pé (IPEA, 2003). Larrañaga e Cybis (2007) calcularam a partir dos dados da EDOM (2004) que, em Porto Alegre, 28\% das viagens são realizadas exclusivamente a pé, revelando a expressiva participação das viagens a pé no sistema de transporte na cidade.

O objetivo deste trabalho é identificar, através de pesquisa qualitativa, os fatores que afetam as decisões individuais de realizar viagens a pé.

\section{REFERENCIAL TEÓRICO}

Na medida em que as externalidades do transporte urbano adquiriram maior severidade, intensificaram-se as pesquisas sobre a mobilidade urbana. A literatura reporta várias pesquisas que investigam a forma como a estrutura físico/urbana do bairro e da cidade afeta a 
mobilidade das pessoas e, em particular, as viagens a pé (Cervero, 1996; Cervero e Radisch, 1996; Cervero e Duncan, 2003; Frank e Pivo, 1995; Greenwald e Boarnet, 2001; Handy e Clifton, 2001; Hess et al., 1999; Naes et al., 1995). Esses estudos evidenciam a correlação entre a configuração física do bairro e os deslocamentos a pé. No entanto, a grande maioria destes trabalhos trata de cidades de países desenvolvidos, especialmente dos Estados Unidos. No Brasil ainda são poucos os estudos que relacionam as características da estrutura urbana e as viagens a pé como em Amâncio, 2005 e Fernandes et al, 2008.

Frank e Pivo (1995) testaram o impacto da diversidade de uso do solo, na utilização de automóvel, transporte público e nos deslocamentos a pé na região de Puget Sound, Estado de Washington. Os autores estudaram, através de regressão multivariada, a existência de uma relação entre forma urbana e escolha modal para as viagens por motivo de trabalho ou compras. Os resultados desta pesquisa mostraram que a maior heterogeneidade do uso do solo nas zonas de origem e destino da viagem está relacionada a uma menor utilização do automóvel e aumento nos deslocamentos a pé.

Cervero e Radisch (1996) analisaram o efeito dos princípios do novo urbanismo nas viagens em dois bairros de São Francisco. O estudo analisou um bairro "tradicional”, que se caracteriza pela compacidade, uso do solo misto e orientação a pedestres, e um bairro "suburbano”, constituído por áreas residenciais localizadas em zonas periféricas das cidades, com pouca densidade populacional e configuração urbana favorecedora à utilização dos modos de transporte motorizados, particularmente automóveis. Os autores estimaram modelos logit binomial para prever a escolha de modos não motorizados. Os resultados revelam que a configuração urbana do bairro influencia significativamente a escolha modal. O bairro compacto, com uso do solo misto e orientado para pedestres, apresenta uma menor utilização do automóvel e um aumento das viagens a pé e por transporte público.

Cervero e Duncan (2003) estudaram a relação entre forma urbana e viagens não motorizadas para a cidade de São Francisco. Utilizaram análise fatorial para representar a configuração urbana e diversidade de uso do solo e, combinando estes fatores com outras variáveis características dos modos não motorizados, construiram modelos de escolha discreta para representar a eleição modal. Os resultados indicam que a diversidade de uso do solo está positivamente relacionada com a decisão de caminhar.

Amâncio (2005) pesquisou a existência de uma relação entre forma urbana e a opção dos indivíduos pelas viagens a pé para a cidade de São Carlos-SP. Utilizou modelos de escolha discreta do tipo logit. Os resultados obtidos permitem inferir que as características do meio físico urbano influenciam a escolha dos indivíduos pelo modo a pé.

Fernandes et al (2008) analisaram a relação entre a forma urbana e o transporte no Município de OlindaPE. Os autores estudaram dois bairros com diferentes características de forma urbana e distintas diretrizes de ordenamento territorial. Os resultados mostram que há uma tendência na redução do deslocamento motorizado quando existe diversidade de uso do solo próximo a residência.

Entretanto, estudos que correlacionam apenas características relativas à estrutura urbana e ao padrão de viagens têm sido criticados por não levar em consideração variáveis sócio-econômicas e outras características que expliquem o estilo de vida e as necessidades de viagens dos residentes. Entre outros fatores, o nível de renda, a estrutura familiar, idade e interesses de lazer variam significativamente entre residentes das diferentes regiões da cidade (Naes, 2005). As diferenças no padrão de viagens podem ser causadas fundamentalmente por esses fatores e não apenas pelas características físicas do bairro de residência. Vários estudos incluíram variáveis sócio-econômicas na análise, mas poucos estudos incluíram variáveis explicativas do estilo de vida dos residentes (Cervero e Duncan, 2002; Hammond, 2005; Cao et al. 2006).

Cervero e Duncan (2002) investigaram a existência de self-selection na cidade de São Francisco através da construção de um modelo logit hierárquico. Selfselection é entendida como a tendência das pessoas de escolherem localizações de residência baseadas nas suas necessidades e preferências de viagem. O modelo desenvolvido calcula a probabilidade de que um indivíduo resida na proximidade de uma estação de metrô e utilize este modo para realizar seus deslocamentos por motivo trabalho. O estudo considera variáveis sócio-econômicas e atitudinais. A pesquisa conclui que a localização residencial e a opção de modo de transporte estão diretamente relacionadas. Os resultados evidenciam a existência de self-selection, sendo que ela explica aproximadamente $40 \%$ das decisões de utilização do modo.

Hammond (2005) estudou a relação entre escolha do local de residência e escolha modal em Century Wharf, Cardiff (cidade do Reino Unido). O autor avaliou, através de questionários diretos, as preferências e atitudes de viagens dos entrevistados (pró-transporte público, pró-caminhada, etc). O estudo concluiu que, para mais da metade dos entrevistados, a escolha modal está associada à escolha de residência.

Cao et al. (2006) analisaram a influência da forma urbana e self-selection nos deslocamentos de pedestres na cidade de Austin (Texas). Os autores avaliaram, através de questionários diretos, se as preferências de 
viagens e as características de uso do solo influenciam a escolha do local de residência. Neste estudo foram estimados modelos binomiais negativos para modelar os impactos do self-selection nos padrões de deslocamentos e freqüências de viagens.

Seguindo as tendências de pesquisas reportadas na literatura, no trabalho apresentado neste artigo foram consideradas, além das características físicas e de urbanização do bairro, características sócio-econômicas e de estilo de vida da população analisada.

\section{METODOLOGIA}

Este trabalho foi desenvolvido a partir de um estudo qualitativo, desenvolvido com o objetivo de investigar os fatores que influenciam a escolha do modo a pé. A pesquisa qualitativa procura a compreensão do objeto de estudo, sem se preocupar com representatividade numérica ou intensidade, permitindo ao pesquisador a obtenção de dados descritivos mediante contato direto e interativo com a situação de estudo. É freqüente que o pesquisador busque entender os fenômenos segundo a perspectiva dos participantes da situação estudada e, a partir daí, situe sua interpretação dos fenômenos estudados (Neves, 1996). Esta abordagem é denominada qualitativa, em contraposição à pesquisa quantitativa, em função da forma de apreensão da realidade e da maneira como os dados são tratados. Embora as abordagens qualitativa e quantitativa difiram enquanto à forma e ênfase, elas não são excludentes (Ariotti et al., 2006).

Os dados foram obtidos através de entrevistas individuais. O objetivo da técnica é explorar o objeto de pesquisa em profundidade, sondando conhecimentos, opiniões, atitudes e sentimentos sobre um tópico em particular, de forma a auxiliar o entendimento de um dado fenômeno. As perguntas e respostas obtidas junto aos entrevistados são analisadas conjuntamente (Ribeiro e Milan, 2004). Neste trabalho, optou-se por utilizar um roteiro semi-estruturado, para assegurar que os tópicos de interesse seriam cobertos. O roteiro utilizado para orientar a condução das entrevistas foi composto pelas questões apresentadas na Tabela 1.

A população alvo desta pesquisa era composta por residentes de duas regiões de Porto Alegre: Centro/Cidade Baixa (Região 1) e Petrópolis/Bela Vista (Região 2). Essas regiões foram escolhidas por apre-

\begin{tabular}{|c|}
\hline $\begin{array}{l}\text { 1. Você utiliza com que freqüência o modo a pé para se } \\
\text { deslocar até destinos próximos à sua residência? Por quê? }\end{array}$ \\
\hline 2. Que elementos você considera quando escolhe caminhar? \\
\hline $\begin{array}{l}\text { 3. Estudos mostraram que o comprimento das quadras entre } \\
\text { interseções, a configuração viária e a topografia do bairro } \\
\text { influenciam a escolha do modo a pé. Você também se } \\
\text { preocupa com esses aspectos? }\end{array}$ \\
\hline 4. Como caracteriza seu bairro? \\
\hline $\begin{array}{l}\text { 5. Seu bairro apresenta características que facilitam o } \\
\text { deslocamento a pé? Quais? }\end{array}$ \\
\hline
\end{tabular}

sentarem respectivamente os maiores e menores percentuais de deslocamentos a pé em relação aos deslocamentos totais originados na região. A partir dos dados da EDOM (2004), Larrañaga (2008) identificou que, no caso do Centro/Cidade Baixa (Figura 1a), praticamente a metade dos deslocamentos totais originados na área são realizados a pé. No caso da região Petrópolis/Bela Vista (Figura 1b), o percentual de deslocamentos a pé corresponde somente a $10 \%$.

A seleção dos entrevistados considerou quatro variáveis de estratificação: localização da residência (Região 1 ou 2), sexo, faixa etária e posse de automóvel. A distribuição das entrevistas foi planejada de forma a obter um equilíbrio entre o número de respondentes em cada estrato. A seleção dos participantes seguiu o plano apresentado na Tabela 2, onde pode ser visto que há exatamente três entrevistados em cada linha e em cada coluna. Isso assegura uma diversidade de respostas, o que é desejável em estudos qualitativos. A Tabela 2 apresenta a distribuição das doze entrevistas realizadas.

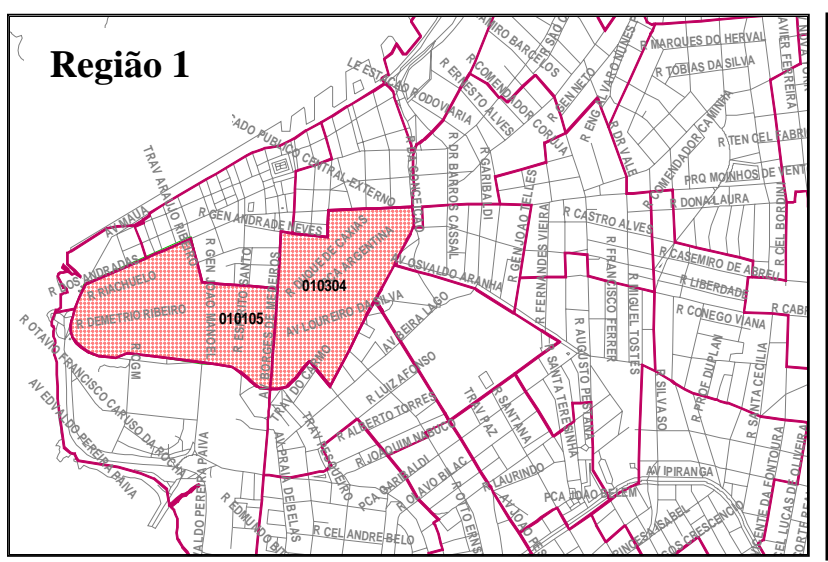

(a)

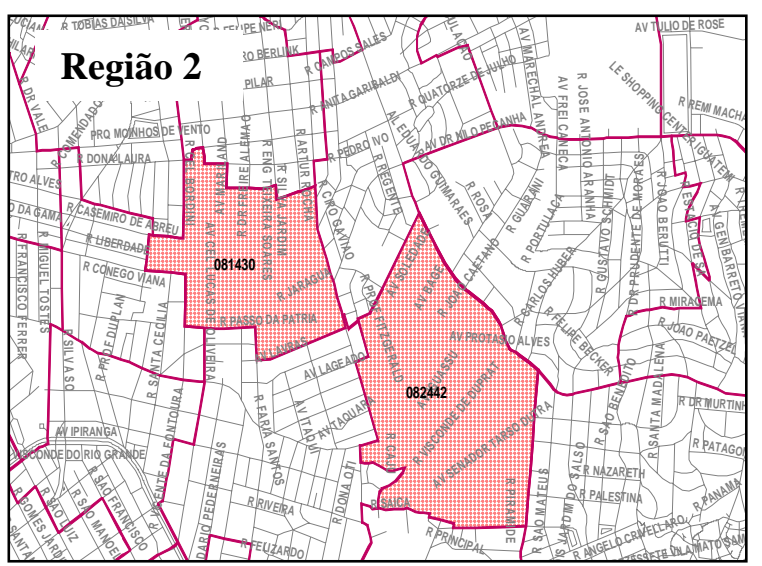

(b)

Figura 1. (a) Região 1-Centro/Cidade Baixa (b) Região 2-Petrópolis/Bela Vista 
Tabela 2. Caracterização da amostra

\begin{tabular}{cccccc}
\hline \multirow{2}{*}{ Sexo } & \multirow{2}{*}{ Faixa etária } & \multicolumn{2}{c}{ Região 1: Centro/Cidade Baixa } & \multicolumn{2}{c}{ Região 2: Petrópolis/Bela Vista } \\
\cline { 3 - 6 } & & com carro & sem carro & com carro & sem carro \\
\hline \multirow{2}{*}{ Mulher } & Jovem/Adulto & $\mathrm{X}$ & $\mathrm{X}$ & $\mathrm{X}$ & $\mathrm{X}$ \\
\cline { 2 - 6 } & $\mathrm{Idoso}(>65$ anos $)$ & & $\mathrm{X}$ & $\mathrm{X}$ & $\mathrm{X}$ \\
\hline \multirow{2}{*}{ Homem } & Jovem/Adulto & $\mathrm{X}$ & & $\mathrm{X}$ & $\mathrm{X}$ \\
\cline { 2 - 6 } & Idoso $(>65$ anos $)$ & $\mathrm{X}$ & $\mathrm{X}$ & $\mathrm{X}$ \\
\hline
\end{tabular}

As entrevistas foram gravadas para obter o maior aproveitamento possível das declarações dos entrevistados. Em alguns casos, as gravações foram complementadas com anotações consideradas importantes. As gravações foram transcritas para posterior análise e interpretação.

\section{DESCRIÇÃO DAS ENTREVISTAS}

As entrevistas foram antecedidas por uma explicação sobre o objetivo da pesquisa e importância da participação do entrevistado na pesquisa. Os entrevistados se mostraram disponíveis para responder as perguntas e interessados no tema de estudo. Todos os entrevistados concordaram com a gravação das entrevistas, mas alguns se mostraram desconfortáveis com o gravador ligado. Nesses casos, respondiam as perguntas de forma concisa, precisando de estímulo para que as informações pudessem ser coletadas. Após desligado o gravador, os entrevistados retornaram às perguntas, comentando-as novamente de forma mais descontraída e fluente. Nesses casos, foram realizadas anotações para complementar as gravações. As perguntas do roteiro são inter-relacionadas. Esta estrutura foi idealizada para permitir que os respondentes pudessem manifestar nas perguntas subseqüentes, alguma informação relevante esquecida anteriormente.

Em resposta à primeira pergunta do roteiro, que questiona sobre a freqüência e os motivos da realização de viagens a pé, os residentes da Região Centro/Cidade Baixa (Região 1) declararam utilizar o modo a pé freqüentemente para realizar suas atividades diárias. Citaram a proximidade de comércios e serviços como um fator motivador para realizar viagens a pé, mas fundamentalmente, comentaram a dificuldade da utilização de outro modal na região para realizar deslocamentos curtos. No caso dos indivíduos que dispõem de automóvel, esta dificuldade deve-se ao excesso de tráfego nas vias, às condições inadequadas de circulação, à indisponibilidade e insegurança de estacionamento na via pública e ao custo elevado dos estacionamentos privados. Comentários dos respondentes envolveram questões como: "Normalmente eu ando a pé no Centro de Porto Alegre, pela facilidade em comparação com circular de ônibus ou de carro. Os congestionamentos dificultam utilizar o carro. É muito difícil encontrar local para estacionar". No caso dos indivíduos que não possuem automóvel, esta dificuldade é devido ao excesso de pessoas nas paradas de ônibus, escassez de linhas em algumas áreas da Região e, em alguns casos, desconhecimento das paradas de ônibus e itinerários das linhas que circulam no Centro. Também comentavam a limitação de mobilidade como fator que motiva a escolha do modo a pé. "Caminho porque não tenho carro".

Para os entrevistados, caminhar permite reduzir custos de transporte, passagem de ônibus ou estacionamento e, também, economizar tempo. Idosos manifestaram o desejo de realizar exercícios físicos em benefício da saúde, realizando caminhadas com destino fixo (ir ao mercado, a padaria, etc) ou por lazer. Declararam que escolhem este modo porque gostam de caminhar. Para alguns jovens, caminhar é uma oportunidade para realizar exercício físico.

Os entrevistados da Região Petrópolis/Bela Vista (Região 2) manifestaram não utilizar o modo a pé com freqüência para realizar deslocamentos curtos no bairro com destino fixo (ir ao banco, à locadora, ao mercado, etc.). Caminham fundamentalmente por lazer, com o propósito de realizar exercícios físicos. Os destinos escolhidos são parques, praças ou espaços públicos abertos. Dois dos entrevistados mencionaram caminhar até um estabelecimento próximo para realizar alguma compra de emergência (por exemplo, falta de algum elemento para preparar uma refeição). Questionados sobre as razões pelas quais não realizam viagens a pé, citaram: (i) a escassez de comércios e serviços na vizinhança próxima; (ii) a preferência por comércios ou serviços mais afastados; (iii) a realização de viagens em cadeia (por exemplo: domicílio-trabalho-supermercado-academia-

domicílio). Estes elementos são comentados a seguir. Em relação à escassez de comércios e serviços na vizinhança próxima, os entrevistados fizeram declarações como: "Não existem alternativas muito próximas a minha residência. O colégio da minha filha e o supermercado ficam longe, não é possível ir a pé". "Não tem nada perto. O mercado mais próximo está a seis quadras da minha casa, eu não vou a pé porque me canso muito. Quando quero realizar compras, meu marido me leva até o mercado e compramos o que precisamos, ou me leva até o cabeleireiro quando preciso". Com referência à preferência de comércios ou serviços mais afastados, os entrevistados comentaram: "Não tem nenhuma boa padaria perto da 
minha casa. Eu prefiro ir mesmo ao supermercado. Geralmente passo no supermercado na volta do trabalho, de carro. O cabeleireiro que eu freqüento fica em outro bairro. Nesse caso também vou de carro, e não trocaria de cabeleireiro embora tivesse outro perto”. Em relação ao último ponto, a realização de viagens em cadeia, os entrevistados disseram: "Faço meus trajetos de carro, programando um roteiro, e quando chego em casa, não quero mais sair”. "Geralmente passo no mercado na volta do trabalho, de carro”.

A segunda pergunta do roteiro pré-estabelecido buscou identificar os elementos que cada entrevistado considera na escolha modal. Foram levantados tanto os elementos que favorecem quanto os que dificultam a escolha do modo a pé. Os fatores citados pelos entrevistados foram: (i) distância da viagem; (ii) horário e dia da viagem; (iii) disponibilidade de automóvel; (iv) disponibilidade de transporte coletivo; (v) estrutura física do bairro (proximidade de comércios e serviços, topografia, qualidade das calçadas, mobiliário urbano); (vi) segurança do bairro; (vii) presença de comércio informal e formal (camelôs, ambulantes, postos de táxi, bancas de revistas); (viii) consumo de tempo; (ix) custo monetário (estacionamento, passagem); (x) limitações físicas da pessoa; (xi) desejo de evitar esforços físicos; (xii) flexibilidade e liberdade na escolha dos trajetos e dos horários da viagem para realizar viagens encadeadas (compras, praticar esporte após o trabalho, levar as crianças à escola); (xiii) desejo de realizar exercícios físicos; (xiv) considerações ambientais; (xv) preferências por um modo de transporte (prazer em caminhar, conforto na utilização do automóvel); (xvi) necessidade de realizar compras de emergência.

$\mathrm{Na}$ terceira questão, pretendeu-se conhecer a opinião do entrevistado sobre a influência de algumas características físicas do bairro: configuração viária, topografia, comprimento de quadras entre interseções. A literatura pesquisada mostra que as configurações físicas do bairro e da rede viária influenciam a mobilidade dos pedestres. Vários estudos concluem que o padrão viário em forma de grelha é o mais adequado para incentivar as viagens a pé. Este tipo de configuração oferece uma maior conectividade entre origem e destino, diminuindo a distância e apresentando ao usuário diferentes opções de rotas (Crane, 1996). Outra característica importante é a dimensão das quadras. Estudos mostram que vias com quadras curtas, com muitas interseções, impedem altas velocidades de circulação para automóveis, favorecendo a circulação de pedestres. Por outro lado, o perfil vertical do terreno do bairro é um fator que influencia a mobilidade dos pedestres. Para os entrevistados, o comprimento das quadras e a configuração viária não são elementos im- portantes na escolha do modo para realizar seus deslocamentos, eles responderam não se preocupar com esses aspectos. Em relação à topografia do terreno, os entrevistados de ambas as regiões estudadas afirmaram que seus bairros apresentam um terreno com muitos aclives e declives. Todos manifestaram que este elemento dificulta a mobilidade do pedestre, mas só algumas pessoas idosas declararam que este fator limita a decisão de caminhar.

As questões 4 e 5 do roteiro se referem à estrutura do bairro. Procuram conhecer as características do bairro que facilitam ou dificultam o deslocamento a pé. Para os entrevistados residentes na Região Centro/Cidade Baixa, o bairro apresenta uma diversidade de atividades, caracterizado por alta densidade de comércios e serviços. As atividades estão próximas, facilitando o deslocamento a pé, e isso é importante na escolha deste modal. Todos os respondentes desta região citaram vários elementos que dificultam os deslocamentos a pé. Entre os elementos mencionados se encontram: (i) condições e dimensões das calçadas; (ii) presença e localização do comércio formal e informal; (iii) localização do mobiliário urbano; (iv) topografia acidentada; (v) fluxo intenso de veículos; (vi) excesso de pessoas nas paradas de transporte coletivo; (vii) insegurança nos cruzamentos; (viii) poluição ambiental (visual e sonora). Estes elementos são comentados a seguir.

De acordo com os entrevistados, as calçadas são estreitas para a utilização pelo pedestre. Eles comentaram que a presença de ambulantes e, inclusive instalações de comercio regular (bancas de revista, pontos de táxi), impedem a circulação do pedestre. Eles acreditam que os vendedores ambulantes deveriam ser alocados a locais mais adequados. Em relação à localização do mobiliário urbano, os entrevistados disseram que o excesso e a má localização de mobiliário urbano (postes de iluminação pública, placas de sinalização, pontos de paradas) dificultam a caminhada de pedestres comuns e, principalmente, das pessoas portadoras de necessidades especiais. Por outro lado, comentaram que os motoristas não respeitam o pedestre e manifestaram insegurança inclusive em travessias sinalizadas. Uma entrevistada comentou que quando chega a um cruzamento ela espera o inicio de um novo ciclo de verde para atravessar a rua mesmo se o semáforo está em verde, devido à insegurança em relação a motoristas mais agressivos. Por último, em relação ao excesso de pessoas nas paradas de transporte coletivo, os entrevistados disseram que, as longas filas nas paradas nos horários de pico bloqueiam a calçada e dificultam a circulação. 


\section{ANÁLISE E INTERPRETAÇÃO DOS DADOS}

A transcrição das entrevistas levou a uma relação de vinte e seis fatores que influenciam a escolha do modo a pé. A partir da identificação destes fatores foi possível agrupá-los, conforme a sua natureza, em quatro categorias: (i) fatores sócio-econômicos; (ii) fatores característicos da viagem; (iii) fatores característicos do bairro; (iv) fatores atitudinais ou relativos ao estilo de vida. Os fatores sócioeconômicos referem-se às características sociais do indivíduo, tais como idade, sexo, estrutura familiar, e às características econômicas do indivíduo, tais como renda, ocupação, posse de automóvel. Os fatores característicos da viagem estão relacionados à natureza da viagem e do modo de transporte disponível para sua realização. Os fatores relativos ao bairro referem-se às características físicas do espaço. Por último, os fatores atitudinais ou de estilo de vida representam as características subjetivas, valores sociais e culturais do indivíduo, que determinam a importância que cada indivíduo atribui aos diferentes aspectos da viagem.

A Tabela 3 sintetiza os fatores identificados pelos

Tabela 3. Fatores intervenientes na escolha do modo a pé e freqüência de manifestações dos entrevistados

\begin{tabular}{|c|c|c|c|}
\hline \multirow{2}{*}{ Classificação } & \multirow{2}{*}{ Fator } & \multicolumn{2}{|c|}{ Freqüência de ocorrência } \\
\hline & & Jovens-Adultos & Idosos \\
\hline Sócio-econômicos & Disponibilidade de automóvel & $\begin{array}{l}\text { Enfatizado por todos os } \\
\text { entrevistados }\end{array}$ & $\begin{array}{l}\text { Enfatizado por mais do que a } \\
\text { metade dos entrevistados }\end{array}$ \\
\hline \multirow{5}{*}{$\begin{array}{l}\text { Características da } \\
\text { viagem }\end{array}$} & Horário e dia da viagem & $\begin{array}{l}\text { Enfatizado por todos os } \\
\text { entrevistados }\end{array}$ & $\begin{array}{l}\text { Enfatizado por todos os } \\
\text { entrevistados }\end{array}$ \\
\hline & Distância da viagem & $\begin{array}{l}\text { Enfatizado por todos os } \\
\text { entrevistados }\end{array}$ & $\begin{array}{l}\text { Enfatizado por todos os } \\
\text { entrevistados }\end{array}$ \\
\hline & Consumo de tempo & $\begin{array}{l}\text { Enfatizado por todos os } \\
\text { entrevistados }\end{array}$ & Não comentado \\
\hline & Custo monetário & $\begin{array}{l}\text { Enfatizado por todos os } \\
\text { entrevistados da Reg. } 1\end{array}$ & $\begin{array}{l}\text { Enfatizado por menos da metade } \\
\text { dos entrevistados da Reg } .1\end{array}$ \\
\hline & $\begin{array}{l}\text { Flexibilidade e liberdade na escolha de } \\
\text { trajetos e momentos do deslocamento }\end{array}$ & $\begin{array}{l}\text { Enfatizado por menos da metade } \\
\text { dos entrevistados da Reg. } 2\end{array}$ & $\begin{array}{l}\text { Enfatizado por menos da metade } \\
\text { dos entrevistados }\end{array}$ \\
\hline \multirow{10}{*}{$\begin{array}{l}\text { Características do } \\
\text { bairro }\end{array}$} & Proximidade de comércios e serviços & $\begin{array}{l}\text { Enfatizado por todos os } \\
\text { entrevistados }\end{array}$ & $\begin{array}{l}\text { Enfatizado por todos os } \\
\text { entrevistados }\end{array}$ \\
\hline & Topografia do terreno & $\begin{array}{l}\text { Enfatizado por menos da metade } \\
\text { dos entrevistados }\end{array}$ & $\begin{array}{l}\text { Enfatizado por menos da metade } \\
\text { dos entrevistados }\end{array}$ \\
\hline & Condições e dimensões das calçadas & $\begin{array}{l}\text { Enfatizado por menos da metade } \\
\text { dos entrevistados }\end{array}$ & $\begin{array}{l}\text { Enfatizado por menos da metade } \\
\text { dos entrevistados }\end{array}$ \\
\hline & Localização do mobiliário urbano & $\begin{array}{l}\text { Enfatizado por menos da metade } \\
\text { dos entrevistados }\end{array}$ & Não comentado \\
\hline & Segurança pública & $\begin{array}{l}\text { Enfatizado por todos os } \\
\text { entrevistados }\end{array}$ & $\begin{array}{l}\text { Enfatizado por todos os } \\
\text { entrevistados }\end{array}$ \\
\hline & $\begin{array}{l}\text { Presença e localização do comércio formal } \\
\text { e informal }\end{array}$ & $\begin{array}{l}\text { Enfatizado por menos da metade } \\
\text { dos entrevistados da Reg. } 1\end{array}$ & $\begin{array}{l}\text { Enfatizado por menos da metade } \\
\text { dos entrevistados da Reg. } 1\end{array}$ \\
\hline & $\begin{array}{l}\text { Características do fluxo de veículos nas } \\
\text { vias }\end{array}$ & $\begin{array}{l}\text { Enfatizado por menos da metade } \\
\text { dos entrevistados da Reg. } 1\end{array}$ & $\begin{array}{l}\text { Enfatizado por menos da metade } \\
\text { dos entrevistados da Região } 1\end{array}$ \\
\hline & $\begin{array}{l}\mathrm{N}^{\circ} \text { de pessoas nas paradas de transporte } \\
\text { coletivo }\end{array}$ & $\begin{array}{l}\text { Enfatizado por menos da metade } \\
\text { dos entrevistados da Reg. } 1\end{array}$ & Não comentado \\
\hline & Características do tráfego nos cruzamentos & Não comentado & $\begin{array}{l}\text { Enfatizado por menos da metade } \\
\text { dos entrevistados da Reg.1 }\end{array}$ \\
\hline & Qualidade do ambiente para pedestres & $\begin{array}{l}\text { Enfatizado por menos da metade } \\
\text { dos entrevistados da Reg. } 2\end{array}$ & $\begin{array}{l}\text { Enfatizado por menos da metade } \\
\text { dos entrevistados da Reg. } 2\end{array}$ \\
\hline \multirow{8}{*}{ Estilo de vida } & Limitações físicas dos usuários & Não comentado & $\begin{array}{l}\text { Enfatizado por todos os } \\
\text { entrevistados }\end{array}$ \\
\hline & Desejo de evitar esforços físicos & $\begin{array}{l}\text { Enfatizado por menos da metade dos } \\
\text { entrevistados }\end{array}$ & Não comentado \\
\hline & Desejo de realizar exercícios físicos & $\begin{array}{l}\text { Enfatizado por mais do que a metade } \\
\text { dos entrevistados }\end{array}$ & $\begin{array}{l}\text { Enfatizado por mais do que a } \\
\text { metade dos entrevistados }\end{array}$ \\
\hline & Considerações ambientais & $\begin{array}{l}\text { Enfatizado por menos da metade dos } \\
\text { entrevistados }\end{array}$ & Não comentado \\
\hline & Preferências de modo de transporte & $\begin{array}{l}\text { Enfatizado por mais do que a metade } \\
\text { dos entrevistados }\end{array}$ & $\begin{array}{l}\text { Enfatizado por mais do que a } \\
\text { metade dos entrevistados }\end{array}$ \\
\hline & Compra de emergência & $\begin{array}{l}\text { Enfatizado por menos da metade } \\
\text { dos entrevistados da Reg. } 2\end{array}$ & Não comentado \\
\hline & Preferência por comércios e serviços & $\begin{array}{l}\text { Enfatizado por todos os } \\
\text { entrevistados da Reg. } 2\end{array}$ & Não comentado \\
\hline & Necessidade de realizar viagens encadeadas & $\begin{array}{l}\text { Enfatizado por mais do que a metade } \\
\text { dos entrevistados da Reg. } 2\end{array}$ & Não comentado \\
\hline
\end{tabular}


entrevistados, sua classificação e freqüência de ocorrência. Conforme a tabela, vários fatores foram mencionados pela maioria dos entrevistados. Inicialmente foram analisados possíveis diferenças das opiniões entre os respondentes femininos e masculinos. Essa análise não revelou diferenças perceptíveis entre os dois sexos. Dentre os fatores sócio-econômicos, todos os respondentes indicaram a disponibilidade de automóvel como um fator interveniente na decisão de caminhar. Cabe salientar que somente este fator sócio-econômico foi declarado, mas existem outros que também foram considerados. Eles são: sexo, faixa etária e renda. Os dois primeiros, sexo e faixa etária, foram utilizados diretamente como variáveis de estratificação para a seleção dos entrevistados. A renda foi considerada de forma implícita na divisão das regiões. A renda média da Região Petrópolis/Bela Vista (Região 2) é entre 2 a 3 vezes maior do que a renda média da Região Centro/Cidade Baixa (Região 1) (Larrañaga, 2008). Estes fatores serão analisados posteriormente.

Muitos dos fatores manifestados pelos entrevistados referem-se a características do bairro. Dentre eles, a segurança pública e a proximidade de comércios e serviços foram citados com maior freqüência. Por último, os fatores atitudinais ou de estilo de vida, variam de acordo com a faixa etária dos respondentes. Para os indivíduos mais jovens, o consumo de tempo, a preferência pelo modo de transporte para realizar uma viagem e o desejo de realizar exercícios físicos foram elementos indicados com freqüência. Para os indivíduos de faixas etárias mais avançadas, as limitações físicas do indivíduo despontaram como determinantes da escolha modal. Estes elementos evidenciam uma diferença em relação à condição física da pessoa.

As manifestações dos entrevistados, analisadas e sintetizadas na Tabela 3 , foram expressas com diferente intensidade. Assim, é possível classificar os fatores de acordo com a intensidade em que foram manifestados e de acordo com a frequiência em que foram mencionados pelos respondentes. Desta forma, foi definida uma escala numérica para representar a intensidade composta por três níveis: 1,2 e 3, em que 3 indica a intensidade maior. A intensidade foi baseada na análise dos registros das entrevistas, observando os adjetivos utilizados pelos participantes. Assim, "muito", "grande”, "intenso" foram associados ao grau 3, quanto "pouco", "pequeno”, "leve” foram associados ao grau 1. Para representar a freqüência foi definida uma escala composta por dois níveis: 0 e 1 . O valor 1 significa que o entrevistado mencionou este fator e 0 o caso contrário. A importância geral de cada fator foi calculada através da seguinte expressão:

$$
I_{k}=\sum_{E} i_{E, k} * f_{E, k}
$$

sendo,
I: importância geral;
$k$ : fator;
$E$ : entrevistado;
$i$ : intensidade da manifestação;
f: freqüência da manifestação.

A partir das manifestações dos entrevistados, os fatores foram classificados em dois tipos: essenciais e facilitadores. Os fatores essenciais, hachurados na Figura 2, são aqueles indispensáveis na escolha do modo a pé. Os fatores facilitadores são aqueles que contribuem para a escolha deste modal, mas não são imprescindíveis para que o indivíduo opte por este modo de transporte. A Figura 2 apresenta a hierarquização dos fatores que motivam a escolha ou facilitam o deslocamento a pé, indicando a importância de cada fator.

Observa-se que os elementos mais influentes na decisão de caminhar variam de acordo com a região e a faixa etária. Na Região Centro/Cidade Baixa, a diversidade de atividades oferecidas no bairro, conjuntamente com a alta densidade de comércios e serviços, permite aproximar as origens e destinos das viagens, reduzindo as distâncias de deslocamento. Analisando o grupo de jovens e adultos, este elemento mostrou ter uma forte influência nos entrevistados, sendo o fator principal que motiva a escolha do modo a pé. Do mesmo modo, as reduções de custo e tempo mostraram ser fatores que motivam fortemente a decisão de caminhar. Analisando o grupo de idosos, o elemento principal na escolha do modo a pé é o desejo de realizar exercícios físicos. Os indivíduos de idade mais avançada caminham fundamentalmente em beneficio da saúde. O gosto por caminhar é outro elemento que influencia fortemente esta decisão. A proximidade de comércios e serviços incentiva a escolha do modal, mas não é um fator desencadeador.

Na Região Petrópolis/Bela Vista, os residentes caminham basicamente por lazer e com o propósito de realizar exercícios físicos. Este elemento é comum às duas faixas etárias, sendo este o único fator referido como essencial para a escolha do modo a pé. Fatores relacionados à qualidade do ambiente para pedestres tais como calçadas largas e em boas condições, pouca densidade de pedestres circulando nas calçadas, cenário agradável para a realização da caminhada e existência de parques, praças e espaços públicos que permitam a realização de caminhadas, são elementos facilitadores, mas não são essenciais para a tomada de decisão. Observa-se uma semelhança entre os elementos essenciais identificados para as pessoas idosas em ambas as áreas. 

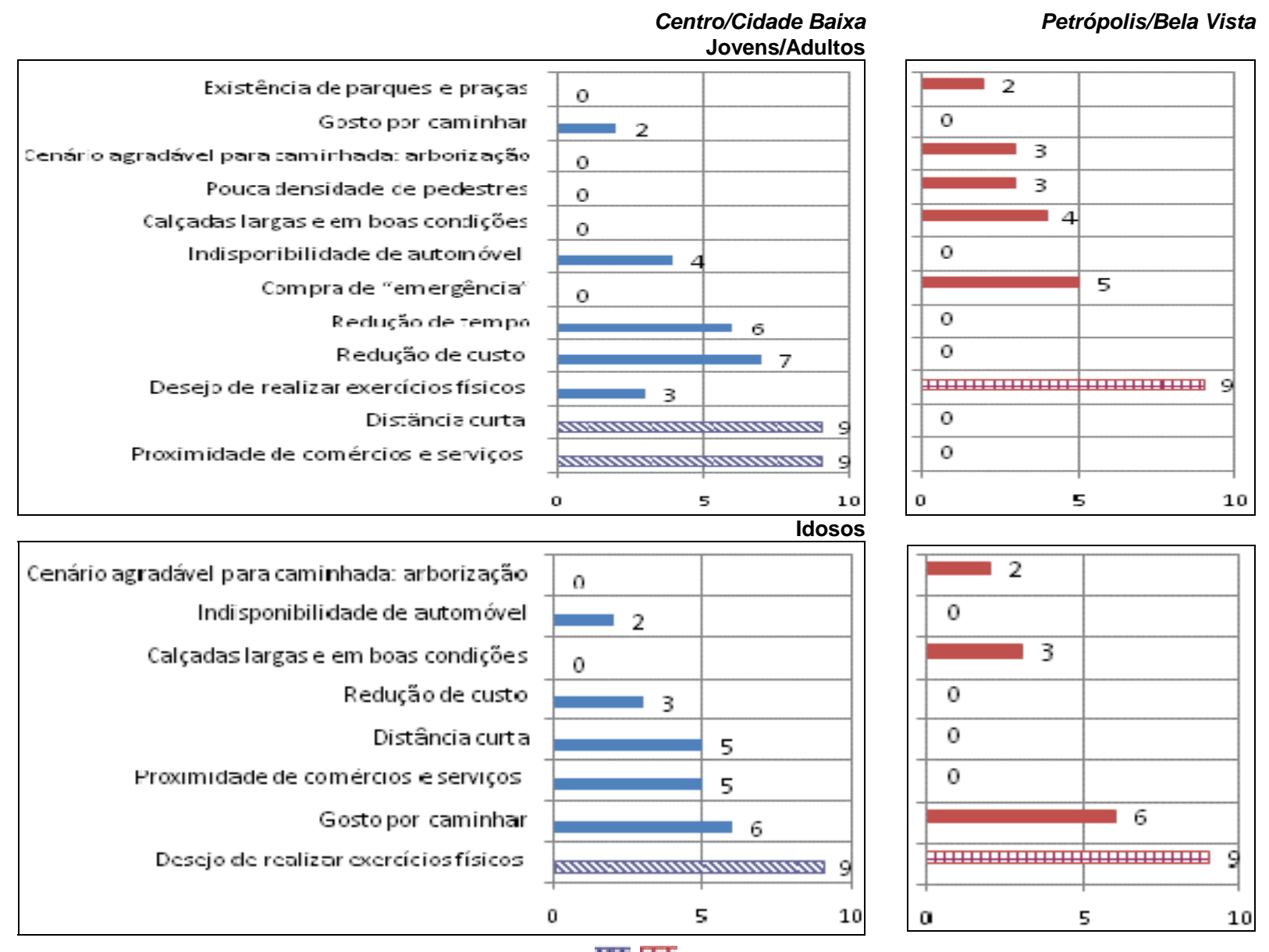

Figura 2. Hierarquização dos elementos que motivam/facilitam a utilização do modo a pé

A Figura 3 apresenta a hierarquização e a pontuação final dos fatores que desmotivam a escolha do modo a pé e os que dificultam, ou mesmo impossibilitam, os deslocamentos. A avaliação dos fatores foi realizada seguindo o mesmo procedimento utilizado na classificação anterior. Da mesma forma que na figura anterior, observa-se variação dos fatores em função da região e faixa etária. Para todos os segmentos de entrevistados segurança pública é uma condição indispensável para realizar deslocamentos a pé. Este elemento está diretamente associado à declaração dos entrevistados de não realizar deslocamentos noturnos a pé, por falta de segurança. Nesse turno, todos os entrevistados optam por outro modo de transporte, independentemente de idade, sexo, bairro ou possibilidade de mobilidade. $\mathrm{Na}$ Região Centro/Cidade Baixa, é possível notar que, para os mais jovens, a distância do percurso é outro fator fundamental na escolha modal. Distâncias longas inibem a escolha do modo a pé, induzindo os indivíduos à seleção de outro modo de transporte.

Nessa região, vários elementos que caracterizam o bairro foram indicados como dificultadores de deslocamentos a pé, mas nenhum destes elementos foi referido como determinante na escolha do modo. As pessoas idosas entrevistadas não referenciaram a distância como um fator preponderante da decisão de caminhar. No entanto, a condição física foi mencionada como um fator limitante para o deslocamento a pé. Este fato provavelmente expressa a consciência das limitações da condição física, que podem inviabilizar deslocamentos a pé, mesmo de curtas distâncias. A presença de aclives e declives foi mencionada como um fator que dificulta o deslocamento a pé. Características do tráfego e demais características físicas do bairro são fatores que influenciam em menor grau a opção pelo modo de transporte.

Na Região Petrópolis/Bela Vista, a escassez de comércios e serviços na vizinhança próxima foi apontada como um dos principais elementos que desmotivam a utilização do modo a pé. Moradores precisam percorrer distâncias mais longas para ter acesso a bens e serviços. Para os entrevistados desta região, os elementos que desmotivam a escolha do modo a pé estão fortemente associados às vantagens oferecidas pelo automóvel. Os residentes desta região, têm maior disponibilidade de automóvel, favorecendo a utilização deste modal. Mesmo os entrevistados que não dispõem de automóvel permanentemente, possuem automóveis no domicilio. Uma justificativa para não realizar viagens a pé bastante mencionada 


\begin{tabular}{|c|c|c|}
\hline & & \\
\hline Desejo de evitar esforços físicos & 0 & \\
\hline № de pessoas nas paradas de transporte coletivo & 1 & \\
\hline Poluição am biental (visual e sonora) & 2 & \\
\hline Preferência pelo uso de automóvel & 0 & \\
\hline Excesso de tráfego nasvias & 3 & \\
\hline Redução de tempo & 0 & \\
\hline Localização inadequada do mobiliário urbano & 4 & \\
\hline Flexibilidade e liberdade na escolha de trajetos e horários da viagem & 0 & \\
\hline Calçadas estreitas e em mau estado & & 5 \\
\hline Presença e localização inadequada de comércio informal e formal & 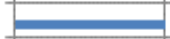 & 5 \\
\hline Viagens encadeadas & 0 & \\
\hline Preferência por com ércios e serviços & 0 & \\
\hline Topografia acidentada & - & -6 \\
\hline Escasse 2 de serviçuse con rércios próximos & 0 & \\
\hline Disponibilidade de automóvel (próprio ou no domicilio) & 0 & \\
\hline Distância muito longa & 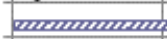 & 8 \\
\hline Falta de segurança pública & 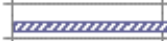 & 9 \\
\hline Deslocamento noturno & mmmmm & mammana 9 \\
\hline & 0 & 10 \\
\hline & & Idosos \\
\hline Prefer ência pela utilização de outro modal & 1 & \\
\hline Flexibilidade e liberdacle na escolha de trajetos e horários da viagem & 0 & \\
\hline Presença e localização inadequada de comércio informal & 2 & \\
\hline Calçadas estreitas e em mau estado & 3 & \\
\hline Preferência por comércios e serviços & 0 & \\
\hline Excesso de tráf ego e insegurança nos cruzamentos & 4 & \\
\hline Excesso de tráfego nasvias & & 5 \\
\hline Distâncias muito longas & 0 & \\
\hline Escassez de serviços e comércios próximos & 0 & \\
\hline Topografia acidentada & & 6 \\
\hline Disponibilidade de automóvel (próprio ou no domicílio) & 0 & \\
\hline Limitaçōes físicas & mImImIm & mamm 8 \\
\hline Falta de segurança pública & mammm & mотытा 9 \\
\hline Desl ocamento noturno & mammmm & 20mimames 9 \\
\hline & 0 & 5 \\
\hline
\end{tabular}
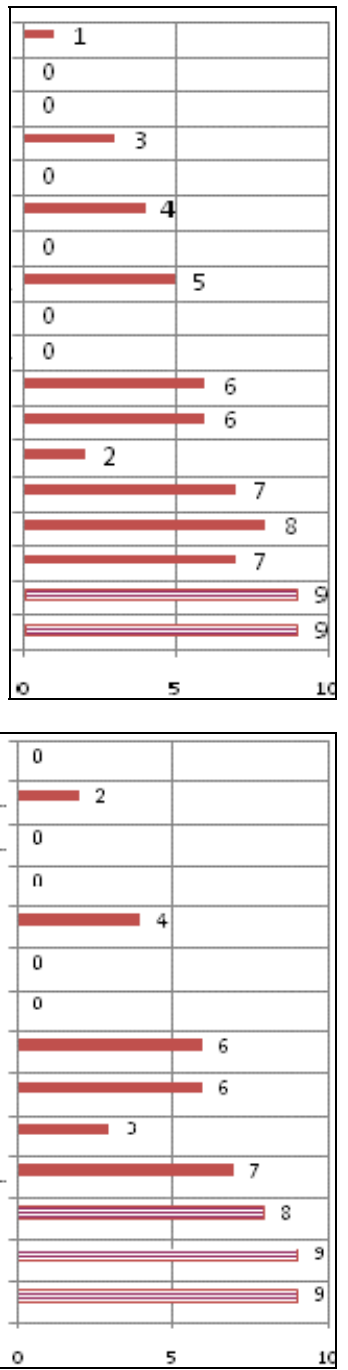

N\$ HI Fatores inibidores

Figura 3. Hierarquização dos elementos que desmotivam/dificultam a utilização do modo a pé

por entrevistados jovens e adultos desta região foi o desejo, ou necessidade, de realizar viagens encadeadas. Para este grupo de entrevistados, as viagens diárias são frequentemente resultado da combinação de várias atividades. Por exemplo, as compras no supermercado são realizadas no retorno do trabalho ou após pegar os filhos no colégio. $\mathrm{O}$ planejamento da viagem envolve a minimização da distância de viagem e a seleção do melhor serviço ou comércio. Desta maneira, as maiores distâncias aos estabelecimentos comerciais são até certo ponto compensadas. Numa perspectiva espaço-tempo, este tipo de comportamento implica que as compras ocupam menor tempo, permitindo ao indivíduo utilizar mais tempo em outras atividades. Além disto, as preferências por comércios ou serviços influenciam fortemente a escolha modal. Os entrevistados selecionam o "melhor" comércio, de acordo com sua valoração pessoal, como por exemplo, o supermercado onde os preços são mais convenientes, ou onde os produtos são de melhor qualidade, ou onde o ambiente é mais agradável. Essa opção pessoal nem sempre coincide com a alternativa de serviço mais próxima.

Interessante ressaltar que os elementos inibidores à realização de viagens a pé identificados pelas pessoas idosas são bastante semelhantes nas duas regiões pesquisadas.

\section{CONCLUSÕES}

Este trabalho apresenta uma pesquisa qualitativa desenvolvida com o objetivo de identificar os fatores que influenciam a decisão de realizar viagens a pé. Os resultados obtidos nas entrevistas permitiram identificar vinte e seis fatores que influenciam a escolha do modo a pé. Esses fatores foram agrupados, de acordo com sua natureza, em quatro grupos: fatores sócio-econômicos, fatores característicos da viagem, fatores relativos à estrutura urbana e fatores atitudinais ou de estilo de vida. Dentre os vinte e seis fatores apresentados, aqueles citados com maior freqüência pelos entrevistados foram: distância da 
viagem, horário da viagem, proximidade de comércios e serviços e segurança pública. Além desses fatores, os indivíduos mais jovens indicaram com freqüência: a preferência pelo modo de transporte para realizar uma viagem, o desejo de realizar exercícios físicos e o tempo de deslocamento. Entretanto, os indivíduos de faixas etárias mais avançadas apontaram as limitações físicas como determinantes da escolha modal.

A análise de freqüência de manifestações dos entrevistados mostrou, conforme esperado, que a estrutura físico/urbana do bairro influencia a decisão de caminhar. Porém, este não é o único elemento que explica o padrão de viagens. A análise de freqüência mostrou que características atitudinais ou de estilo de vida também influenciam a escolha do modo a pé, confirmando a importância de incluir essas variáveis nos estudos de planejamento urbano.

Os resultados da análise de hierarquização mostraram que o alto número de deslocamentos a pé observado na Região Centro/Cidade Baixa se deve à diversidade de uso do solo e à dificuldade de utilizar modos alternativos. Em contraposição, o número reduzido de viagens a pé na Região Petrópolis/Bela Vista, se deve não somente à escassez de comércios e serviços na vizinhança próxima, mas à disponibilidade de automóvel no domicílio, à preferência por comércios e serviços mais afastados e ao hábito de realizar viagens em cadeia. Estes elementos desmotivam a utilização do modo a pé, incentivando a utilização de modais alternativos, predominantemente automóvel.

Observou-se uma maior concordância, entre os grupos de entrevistados, na identificação de fatores inibidores do que na relação de fatores que estimulam as viagens a pé. Analisando as respostas de entrevistados segundo a faixa etária, observa-se uma maior concordância entre idosos das duas regiões do que entre os entrevistados mais jovens, particularmente em relação aos quesitos considerados essenciais. Variáveis sócio-econômicas tem sido tradicionalmente consideradas como variáveis chave para explicar decisões na área de transportes. Os resultados desta pesquisa indicam, entretanto, que alguns fatores característicos do ambiente social e das particularidades individuais podem ser mais importantes que o nível sócio-econômico para explicar as escolhas de modo de viagem. A insegurança em relação a assaltos e o medo de realizar deslocamentos a pé à noite, foram pontos comuns a todos os entrevistados. A importância atribuída a estes fatores se sobrepõe a outras questões associadas a nivel de renda. As restrições físicas inerentes a pessoas idosas foi um ponto comum apontado por entrevistados das duas regiões e também se sobrepõe a todas às outras questões apontadas.

Os resultados da pesquisa permitem concluir que, conforme reportado na literatura, a configuração do bairro influencia a decisão de caminhar, indicando que a estrutura físico/urbana do bairro é um elemento chave para explicar o padrão de deslocamentos a pé. Entretanto, características atitudinais ou de estilo de vida dos indivíduos também influenciam o padrão de deslocamentos a pé, indicando que elementos que caracterizam a estrutura físico /urbana do bairro podem não ser suficientes para explicar o padrão de deslocamentos em centros urbanos. É fundamental considerar as características sócio-econômicas e de estilo de vida dos usuários na elaboração de projetos urbanísticos e de transportes.

Considerando a diversidade de características, valores e necessidades de individuos nas grandes áreas urbanas, pesquisas qualitativas são instrumentos importantes para auxiliar na compreensão dos processos decisórios associados ao planejamento de transportes. Resultados encontrados neste trabalho podem fornecer importantes subsídeos para o desenvolvimento de novas pesquisas que visem o desenvolvimento de sistemas de transportes e ambientes mais sustentáveis.

\section{REFERÊNCIAS}

Amâncio, M.A.(2005) Relacionamento entre a forma urbana e as viagens $a$ pé. Dissertação de Mestrado. Departamento de Engenharia Civil, Universidade Federal de São Carlos, São Paulo.

Ariotti, P.; Cybis, H.B.; Ribeiro, J.L.D. (2006) Fatores intervenientes no comportamento de pedestres em travessias semaforizadas: uma abordagem qualitativa. Transporte em Transformação $X X$ CNT/ANPET, p.59-75, Brasília.

Cao, X.; Handy, S.; Mokhtarian, P. (2006) The Influences of the Built Environment and Residential Self-Selection on Pedestrian Behavior. Transportation, in press.

Cervero, R. (1996) Mixed land uses and commuting: Evidence from the American Housing Survey. Transportation Research A 30 (5): 361-77.

Cervero, R; Duncan, M. (2002) Residential Self Selection and Rail Commuting: A Nested Logit Analysis. University of California Transportation Center, Berkeley, CA, http://www.uctc.net/papers/604.pdf

Cervero, R.; Duncan, M. (2003) Walking, bicycling, and urban landscapes: evidence from San Francisco Bay Area. American Journal of Public Health 93:(9), 1478-1483.

Cervero, R; Radisch, C. (1996) Travel choices in pedestrian versus automobile oriented neighborhoods. Transport Policy 3:(3), 127 141.

Crane, R. (1996) On form versus function: Will the new urbanism reduce traffic, or increase it? Journal of Planning Education and Research 15 (2): 117-26.

Fernandes, K.D.L.M;Maia, M.L.A;Ferraz, C. (2008) Forma urbana e deslocamentos pendulares:uma análise dos bairros de Casa Caiada e Jardim Braisl em Olinda-PE. In: XXII ANPET Congresso de Pesquisa e Ensino em Transportes, 2008, Fortaleza. Panorama Nacional de Pesquisa e Ensino em Transportes 2008, v.1 p.763775.

Frank L.D.; Pivo, G. (1995) Impacts of mixed use and density on utilization of three modes of travel: single-occupant vehicle, transit, and walking. Transportation Research Record 1466: 44 52.

Greenwald, M. J.; Boarnet, M.G. (2001) Built environment as determinant of walking behavior: analyzing nonwork pedestrian travel in Portland, Oregon. Transportation Research Record 1780: 33-42. 
Handy, S. L. (2002) How the built environment affects physical activity. Views from Urban Planning. American Journal of Preventive Medicine 23(2).p.64-73.

Handy, S. L.; Clifton, K. (2001) Evaluating Neighborhood Accessibility: Issues and Methods Using Geographic Information Systems, Report SWUTC/00/167202-1. Southwest Region University Transportation Center, Center for Transportation Research, The University of Texas at Austin.

Hammond, D. (2005). Residential Location and Commute Mode Choice. Dissertação de Mestrado em Transporte, University of Wales, Cardiff.

Hess, P. M.; Moudon, A.V.; Snyder, M.C.; Stanilov, K. (1999) Site design and pedestrian travel. Transportation Research Record 1674: 9-19.

IPEA (2003) Impactos Sociais e Econômicos dos Acidentes de Trânsito nas Aglomerações Urbanas Brasileiras. Instituto de Pesquisa Econômica Aplicada, Brasília, D.F.

Larrañaga, A.M. ; Cybis, H.B. (2007) Análise do padrão comportamental de pedestres. In: XXI ANPET Congresso de Pesquisa e Ensino em Transportes, 2007, Rio de Janeiro. Panorama Nacional de Pesquisa e Ensino em Transportes 2007. Rio de Janeiro.

Larrañaga, A.M. (2008) Análise do Padrão comportamental de pedestres. Dissertação de Mestrado. Departamento de Produção e Transportes. Universidade Federal do Rio Grande do Sul, Porto Alegre, RS.

Litman, T. (2003) London Congestion Pricing: Implications for other cities. Victoria Transport Policy Institute, Victoria.

Naes P.; Roe .G.; Larsen S.L. (1995) Travelling distances, modal split and transportation energy in thurty residential areas in Oslo, Journal of Environmental Planning and Management 38. p349-370.

Naes, P. (2005) Residential location affects travel behavior-but how and why? The case of Copenhagen metropolitan area. Progress in Planning, Volume 63, Issue 2, p. 167-257.

Neves, J.L. (1996) Pesquisa Qualitativa-Características, usos e possibilidades. Caderno de Pesquisas em Administração. V.1, No 3.

Ribeiro, J.L.D.; Milan, G.S. (2004) Entrevistas Individuais: teoria $e$ aplicações. FEEng/UFRGS, Porto Alegre, RS. 